\title{
Effect of Square-Stepping Exercise in Improving Lower Extremity Strength, Cadence and Confidence among Female Geriatric Population
}

\author{
Arun Thachil ${ }^{1}$, Leya Thomas ${ }^{2}$ \\ ${ }^{1}$ Professor, College of Physiotherapy, Medical Trust Institute of Medical Sciences, Kochi- 682309. \\ ${ }^{2}$ P.G. Student, (Musculoskeletal), College of Physiotherapy, Medical Trust Institute of Medical Sciences, \\ Kochi- 682309. \\ Corresponding Author: Arun Thachil
}

DOI: https://doi.org/10.52403/ijhsr.20220240

\begin{abstract}
Background and Objectives: Falls are frequent among elderly people. Fear of falling can become incapacitating and predisposes people who perceive themselves at risk of falling to inactivity, which itself can lead to problems of debilitation, increased handicap, and disability. Due to fear of fall, the elderly develops social isolation, a reduction in their confidence to accomplish normal activities of daily living, and mobility problems, and adopt an inactive life style, functional decline, resulting in institutionalization. Parameters like lower extremity strength, cadence and confidence are important for fall prevention. This study was designed to investigate effect of Square- Stepping Exercise (SSE) in improving lower extremity strength, cadence and confidence among female geriatric population.

Methodology: 30 subjects from 1) FCC Convent \& Assissi old age home, and 2) Mundakapadam Agathimandiram, were recruited for the study through convenient sampling. Activities- specific Balance Confidence $(\mathrm{ABC})$ scale questionnaire was taken as an inclusion criteria and those who score below $80 \%$ was considered to be included in the study. After baseline measurement, 30 subjects satisfying the inclusion criteria were assigned into either a control group (Group $A, n=15$ ) and experimental group (Group B, $\mathrm{n}=15$ ). Pre-test analysis was performed for both groups for lower extremity strength using hand-held dynamometer, cadence using $10 \mathrm{M}$ walk test and confidence using ABC Scale questionnaire sheets. Experimental group received SSE in addition to conventional exercise whereas; control group received conventional exercise for 4 weeks. Post-test analysis was conducted. Statistical analysis was performed. Paired t test analysed the within group changes, independent $t$ test was used to compare the changes between the group. Level of significance was kept at $\mathrm{p} \leq 0.05$.
\end{abstract}

Results: There was a significant improvement in lower extremity strength, cadence and confidence within group analysis. While comparing the control and experimental group, the experimental group showed a high significant difference $(\mathrm{p}<0.05)$ in lower extremity strength and confidence. Cadence shown no significant difference ( $\mathrm{p}>0.05$ ) between the group analysis.

Conclusion: This study revealed that Square-stepping exercise provided a significant improvement in lower extremity strength and confidence with $p \leq 0.05$. Improvement in these physical parameters will reduce the risk of fall in young-old female geriatric population. SSE is safe to administer and advantageous to prevent falls.

Keywords: Square stepping exercise; Older adults; Fall; Fear of fall; Balance confidence; Strength; Cadence

\section{INTRODUCTION}

Falls are frequent among elderly people. ${ }^{1}$ According to Lamb et.al, 2005, a fall is defined as 'An unexpected event in which the participant comes to rest on the ground, floor or lower level'. ${ }^{2}$ Falls are 
common throughout the life span, but the consequences of a fall event vary depending on the person's age. The incidence of falling increases with age.

Falls represent the most common mechanism of injury, and the leading cause of death from injury, in people older than age 65 years.

The Centers for Disease Control and Prevention reported that in 2004, nearly 15,800 people aged 65 years and older died from injuries related to unintentional falls, and another 1.8 million were treated in emergency departments for non-fatal injuries from falls. Of those who fall, $10 \%$ have a serious injury (fracture, dislocation, or head injury). In 2000, medical treatment for falls among people older than age 65 years cost the United States more than \$19 billion, and the number is projected to increase to $\$ 43.8$ billion by $2020 .^{3}$

Falls in older adults are a major concern and are a major cause of morbidity and mortality. Falls are multifaceted and a heterogeneous problem. ${ }^{3}$ Falls present a substantial health problem among the elderly population. Fall related injuries are leading cause of non-fatal injuries. Its consequences often extending far beyond minor injury to significant loss of functional independence and even death.

The three division of elderly are; Young-old group consists of the population between 65 and 75, in Middle-old group consists between 75 and 85 and Old-old group consists between older than 85 years of age. ${ }^{4}$

The number of persons above the age of 60 years is fast growing, especially in India. India as the second most populous country in the world has 76.6 million people at or over the age of 60 constituting above $7.7 \%$ of total population. ${ }^{5}$

Fall rates in persons over 65 years of age or older are at least $33 \%$ per year in being found to fall more frequently than men (Campbell et. al., 1981; Nevitt et. al., 1989; Shumway- Cook et. al., 2009). At least one third of people aged 65 years and above fall every year, half of them more than once, ${ }^{6}$ and the incidence increases with advancing age. ${ }^{7}$ Women are more prone to falling compared to men and sustain more fall related injuries. ${ }^{8}$ The annual rates of non-fatal injuries due to falls for women have been reported to be $48.4 \%$ higher than the rates for men. ${ }^{9}$

Falls in elderly is a major public health problem with substantial medical and economic consequences. In $15 \%$ individuals, complications of falls include fractures, bruises, soft tissue injuries and loss of independence. Serious injury occurs in $6 \%$ of the elderly population causing accidental death. Fallers who did not suffer serious injuries may experience restriction in ADLs. As a result, the elderly population develops fear of falling and adopts lifestyle of inactivity resulting in significant muscular atrophy leading to decline in lower extremity strength. ${ }^{10}$

Fear of falling can become incapacitating and predisposes people who perceive themselves at risk of falling to inactivity, ${ }^{11}$ which itself can lead to problems of debilitation, increased handicap, and disability. The fear of falling can have detrimental effects on physical function in the elderly population. ${ }^{10}$ The elderly have at least 10 times higher risk of falling than other age groups because of age- related physiological changes, especially those pertaining to the quality of skeletal muscles. ${ }^{12}$ Due to fear of fall, the elderly develop social isolation, a reduction in their confidence to accomplish normal activities of daily living, and mobility problems, and adopt an inactive life style, functional decline, resulting in institutionalization.

Low balance confidence (BC) and / or falls self- efficacy is a major health problem among older adults restricting their participation in daily life, which can lead to avoidance of activities, causing restriction of physical activities and participation in daily life. This restriction can result in physical frailty, falls and loss of independence. ${ }^{(13,14,15,16,17,18)}$ 
About $30 \%-50 \%$ of falls in the elderly result in minor injuries, including bruises, abrasions, and lacerations, but an estimated $10 \%$ of all falls in seniors cause major injuries, including intracranial injuries (ICIs) and fractures. One percent of all falls in this population result in hip fractures, which pose a significant risk for post fall morbidity and mortality. ${ }^{(19,20)}$ In addition, according to the Centers for Disease Control and Prevention (CDC), between 2006 and 2010, falls were the leading cause of traumatic brain injuryrelated deaths in persons aged 65 or older. ${ }^{21}$

One major difference in the geriatric population is skeletal fragility ${ }^{22}$ which occurs as their bones become more susceptible to the mechanical forces or trauma. Consequently, elderly patients will sustain more severe injuries with lower force mechanisms than their younger counterparts, who have greater bone density. Skeletal tissue is remarkably susceptible to change in response to day- today changes occur in addition to the ongoing decline in bone mineral that begins in the $3^{\text {rd }}$ decade and continues on through life. $^{3}$

It is well known that women have a faster rate of bone mass loss during the menopause, where the typical yearly decrease of $0.5 \%$ to $1 \%$ doubles to about $2 \%$ per year for the 5 years peri- and menopausal era. The natural decline in bone mineral content may predispose patients to

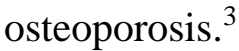

An estimated $75 \%$ of all vertebral and non- vertebral fractures occur in the aged 65 years or older, and more than $75 \%$ of hip fractures affect seniors aged 75 years or older. ${ }^{23}$ Fractures are an independent predictor of long- term mortality. After a hip fracture, an elderly person has a $27 \%$ chance of dying within 1 year, ${ }^{24}$ following a proximal femur fracture, $50 \%$ of affected seniors will experience a functional decline within 1 year. ${ }^{25}$ Other post fall fracture sites in older people include the proximal humerus, pelvis, vertebrae, distal radius, and vertebral bodies. ${ }^{26}$
Fear of falling may lead to more sedentary lifestyle with subsequent deconditioning that creates an ongoing downward spiral leading to frailty and increased risk of future falls. Fear of falling has been associated with the use of a walking device, balance impairment, depression, trait anxiety, female gender, and a previous history of a fall or falls. ${ }^{3}$

Lower extremity muscle weakness has been associated with decreased speed of gait and decreased performance on functional measures by many authors. ${ }^{3}$ The muscle strength of knee extensors decreased earlier in the female than in the male population. In women, this muscle strength declined significantly from the age of 70 years, but from the age of 80 years in men. According to a literature review, the muscle strength of knee extensors was associated with many functional activities. The decline of functional activities with aging began earlier in women than in men. ${ }^{27}$ Ikezoe et. $\mathrm{al},{ }^{28}$ noted that the antigravity muscles, such as quadriceps, are the most affected by the inactivity. In addition, knee extensors weakness is the important predict factor for falls. $^{29}$

As the age advances, there is significant reduction in the cross- sectional area of the muscles. The reduced muscle mass may result into reduced physical activity and disuse atrophy which further aggravates the reduction in muscle mass as well as muscle strength. Decreased fitness of the lower extremities is a potentially modifiable fall risk factor. Cognitive factors such as fear of falling may also be an important contributor to reduced cadence taken by the elderly.

Square- stepping exercise (SSE) is a low- cost indoor program, composed of multidirectional steps in the forward, backward, lateral, and oblique directions. SSE is a more useful exercise program than regular walking for older adults; thus it may serve as a new form of exercise to prevent falls. The benefit of SSE also extends beyond preventing fall such as improving functional ability, fitness of lower 
Arun Thachil et.al. Effect of square-stepping exercise in improving lower extremity strength, cadence and confidence among female geriatric population.

extremities, and health status among older adults (Shigematsu et. al, 2008a; Shigematsu et. al, 2008b).

\section{METHODOLOGY}

Study Design: Experimental study Sampling Technique: Convenient sampling

Sample Size: 30 subjects

Selection of Subjects: Based on ABC scale scoring less than $80 \%$.

Study Duration: 4 weeks- 3 sessions per week

Study setting: FCC Convent \& Assissi old age home, Kottayam; and Mundakapadam Agathimandiram, Kottayam.

\section{Inclusion Criteria}

- Female population

- Young old adults (65- 75 years of age)

- Activities- specific Balance Confidence (ABC) scale with scoring of below $80 \%$

- Those who are leading a sedentary lifestyle.

\section{Exclusion Criteria}

- Activities- specific Balance Confidence (ABC) scale with scoring of above $80 \%$

- Visual and auditory impairment

- Those who are not willing to participate in the study

\section{Outcome Measures}

- Hand- held dynamometer to measure lower extremity strength- Quadriceps strength (KERN MAP- version 1.2 08/2012) and capacity of $40 \mathrm{~kg}$ (green).

- 10 meter walk test to measure cadence.

- $\mathrm{ABC}$ scale to measure confidence

\section{Materials Required}

- Square stepping mats

- Hand held dynamometer

- ABC scale questionnaire sheets

- Measuring tape

- Insulation tape

- Chalk

- Stopwatch

\section{Procedure}

The study was designed to determine the effect of Square- stepping exercise in improving lower extremity strength, cadence, and confidence among female geriatric population. Ethical clearance was obtained from the ethical committee of Medical Trust Hospital, Kochi. Permission had taken from respective authorities of the institutions. Two group pre test-post test design was used with convenient sampling.

The study involved young- old female geriatric population, recruited from

1) FCC Convent \& Assissi old age home, Kolladu, Poovanthuruthu, Kottayam.

2) Mundakapadam Agathimandiram,Manganam, Kottayam.

The study was an Experimental study. Activities- specific Balance Confidence (ABC) scale questionnaire sheets were given to the female participants at the study setting, and those who score below $80 \%$ was considered to be included in the study. After baseline measurement, 30 subjects satisfying the inclusion criteria were assigned using convenient sampling to either a Control group (Group A, n=15) in which conventional exercises were given and an Experimental Group (Group B, $\mathrm{n}=15$ ) in which square stepping exercise and conventional exercises were given. Both Group A and Group B received conventional exercises for 20-30 minutes with 3 sessions per week, for 4 weeks.

Group B - Experimental group - in addition to conventional exercises received square stepping exercise with each session comprised of 5 minutes of warm- up activities, 30 minutes of SSE and 5 minutes of cool- down activities under supervision with 3 sessions per week, for 4 weeks.

Square stepping exercise (SSE) comprises multiple directional step patterns performed on a thin mat $(100 \times 250 \mathrm{~cm})$ that is partitioned into 40 squares $(25 \mathrm{~cm}$ each). The patterns of SSE used were Elementary 1 and 2, Intermediate 1, and Advanced 3 categories. Four mats were used for each 
patterns. The persons were instructed to walk (step) from one end of the mat to the other according to the step pattern provided. When the person reached the end of the mat, they were instructed to return to their start positions by walking normally off the mat and then stand for the next stepping. After the persons become familiar with each of the step patterns, they were instructed to perform toe walking as a progression, without treading on the frames of the squares. Each step pattern was repeated 410 times to ensure that the persons could complete the pattern. Each step pattern should be completed within 15 seconds.

Group A -Conventional group intervention includes training of subjects to do backward walking, sideways walking, forward walking, walking on high knees with emphasis on taking long steps and arm swinging.

Pre-treatment score was taken before the commencement of the treatment session and post- treatment score was taken after the completion of 4 weeks of treatment session.

\section{Hand- held dynamometer}

Test procedure: Hand- held dynamometer used was KERN MAP (version 1.2 08/2012) and capacity of $40 \mathrm{~kg}$ (green). A detailed explanation was given to the participant about the procedure. Isometric knee extensor strength was measured with the participant seated and hip and knees flexed at $90^{\circ}$. Dynamometer is placed on the anterior aspect of the shank, proximal to the ankle joint.

\section{Meter Walk test}

Test procedure: The 10 meter walk test (10MWT) was the tool used to evaluate the spatial, temporal, and kinematic attributes of gait. A detailed explanation was given to the participant about the procedure. To eliminate the acceleration and deceleration components, the volunteers were instructed to begin walking $1.2 \mathrm{~m}$ before the beginning of the course and to finish $1.2 \mathrm{~m}$ after the end of the course at usual speed. Three tests were carried out to minimize the learning effect, and the performance was used for data analysis. Using stopwatch, walking time of all volunteers and registered the number of steps and strides were taken during the course. Using these data, the cadence was estimated.

\section{ABC Scale Questionnaire}

Test procedure: Activities- specific Balance Confidence Scale $(\mathrm{ABC}=16)$ is a common tool for assessing. ABC scale was translated to local language. It consists of 16 situation- specific activities including both indoors and outdoors task. A detailed explanation was given to the participant about the procedure. For each of the following activities, the participant is asked to indicate their level of confidence in doing the activity without losing their balance or become unsteady from choosing one of the percentage points on the scale from $0 \%$ to $100 \%$. If the participant is currently not doing the activity in question, try and imagine how confident if they had to do the activity or hold onto someone, rate the confidence as if they were using these supports.

\section{Statistical analysis and interpretations.}

All the statistical analysis and graph preparations were performed using SPSS and Microsoft Excel. Paired t test was used for intra group comparison of pre- post test results and unpaired $t$ test was used to determine the effect between experimental and control group. The dependent variables were Quadriceps muscle strength, cadence and confidence and the independent variables were Square- stepping exercise as well as conventional exercise. Significance level was kept at $\mathrm{p}<0.05$ with $95 \%$ confidence interval.

\section{Comparison of pre-test and post-test values of Quadriceps strength (Left) within Control Group}

The Mean column in the pairedsamples $t$ test table displays the mean pretest and post-test Quadriceps strength (left) scores. The Standard Deviation column 
Arun Thachil et.al. Effect of square-stepping exercise in improving lower extremity strength, cadence and confidence among female geriatric population.

displays the standard deviation of the pre and post scores. The analysis of pre-test and post-test values of Quadriceps strength (left) revealed that there was a difference of 0.68 between the pre test and post test values. $\mathrm{t}$ value calculated was 5.92 which is greater than the table value at $5 \%$ level of significance $(\mathrm{p}<0.05)$.

Table 1: Paired t test of Quadriceps Strength (Left) within control group

\begin{tabular}{|l|l|l|l|l|l|l|}
\hline Quadriceps Strength (Left) & Mean & Std. Deviation & Mean Difference & t & df & Significance \\
\hline Pre-test & 6.48 & 1.11 & 0.68 & & & \\
\cline { 1 - 3 } Post-test & 7.16 & 1.35 & & 5.92 & 14 & $\mathrm{p}<0.05$ \\
\hline
\end{tabular}

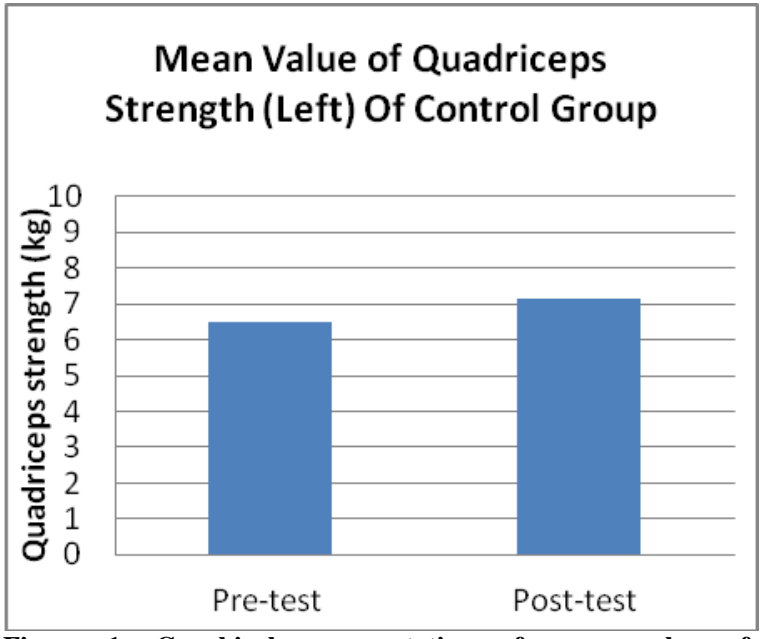

Figure 1: Graphical representation of mean value of Quadriceps Strength (Left) within control group.

\section{Comparison of pre-test and post-test values of Quadriceps strength (Right) within Control Group}

The Mean column in the pairedsamples $t$ test table displays the mean pretest and post-test Quadriceps strength (right) scores. The Standard Deviation column displays the standard deviation of the pre and post scores.

The analysis of pre-test and post-test values of Quadriceps strength (right) revealed that there was a difference of 0.86 between the pre test and post test values. $\mathrm{t}-$ value calculated was 3.24 which is greater than the table value at $5 \%$ level of significance $(\mathrm{p}<0.05)$.

Table 2: Paired t test of Quadriceps Strength (Right) within control group

\begin{tabular}{|l|l|l|l|l|l|l|}
\hline Quadriceps Strength (Right) & Mean & Std. Deviation & Mean Difference & t & df & Significance \\
\hline Pre-test & 6.12 & 1.99 & 0.86 & & & \\
\cline { 1 - 4 } Post-test & 6.98 & 2.05 & & 3.24 & 14 & $\mathrm{P}<0.05$ \\
\hline
\end{tabular}

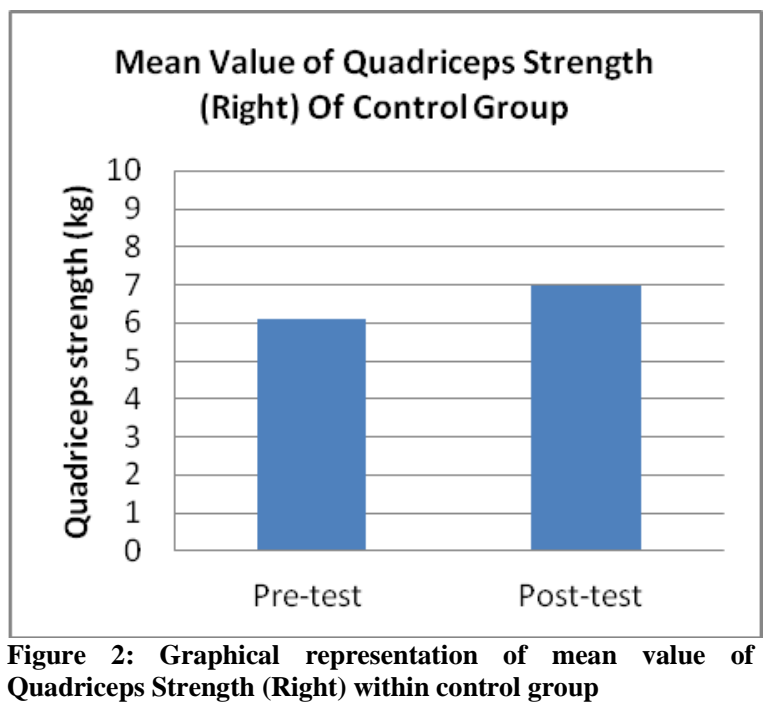

Comparison of pre-test and post-test values of Cadence within Control Group

The Mean column in the pairedsamples $t$ test table displays the mean pretest and post-test values of cadence. The Standard Deviation column displays the standard deviation of the pre and post scores.

The analysis of pre-test and post-test values of cadence revealed that there was a difference of 4.2 between the pre test and post test values. t-value calculated was 5.13 which is greater than the table value at $5 \%$ level of significance $(\mathrm{p}<0.05)$.

Table 3: Paired t test of Cadence within control group

\begin{tabular}{|l|l|l|l|l|l|l|}
\hline Cadence & Mean & Std. Deviation & Mean Difference & t & Df & Significance \\
\hline Pre-test & 94.2 & 14.68 & 4.2 & & & \\
\cline { 1 - 2 } Post-test & 98.4 & 13.58 & & 5.13 & 14 & $\mathrm{P}<0.05$ \\
\hline
\end{tabular}


Arun Thachil et.al. Effect of square-stepping exercise in improving lower extremity strength, cadence and confidence among female geriatric population.

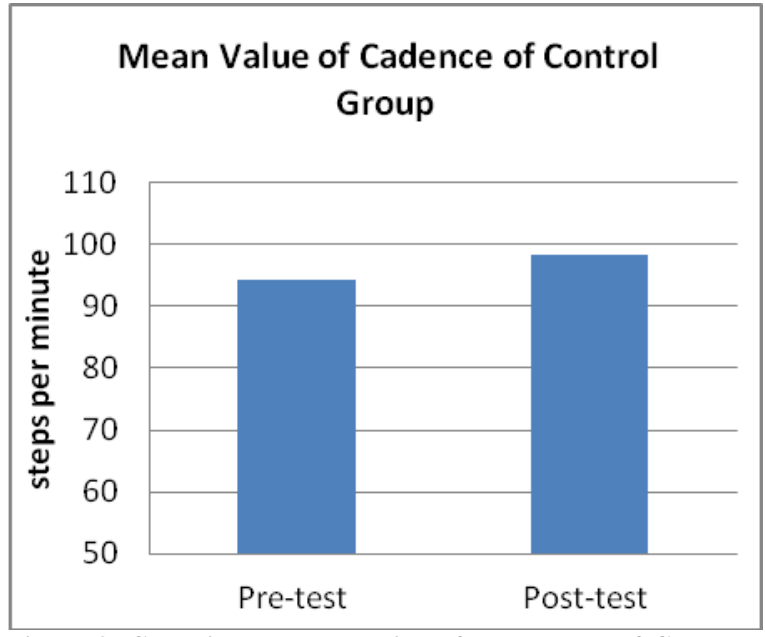

Figure 3: Graphical representation of mean value of Cadence within control group

\section{Comparison of pre-test and post-test values of Confidence within Control Group}

The Mean column in the paired-samples $t$ test table displays the mean pre-test and post-test confidence scores. The Standard Deviation column displays the standard deviation of the pre and post scores.

The analysis of pre-test and post-test values of confidence revealed that there was a difference of 11.84 between the pre test and post test values. $t$-value calculated was 8.68 which is greater than the table value at $5 \%$ level of significance $(\mathrm{p}<0.05)$.

Table 4: Paired t test of Confidence within control group

\begin{tabular}{|l|l|l|l|l|l|l|}
\hline Confidence & Mean & Std. Deviation & Mean Difference & t & df & Significance \\
\hline Pre-test & 58.9 & 7.21 & 11.84 & 8.68 & 14 & $\mathrm{P}<0.05$ \\
\cline { 1 - 3 } Post-test & 70.74 & 9.58 & & & & \\
\hline
\end{tabular}

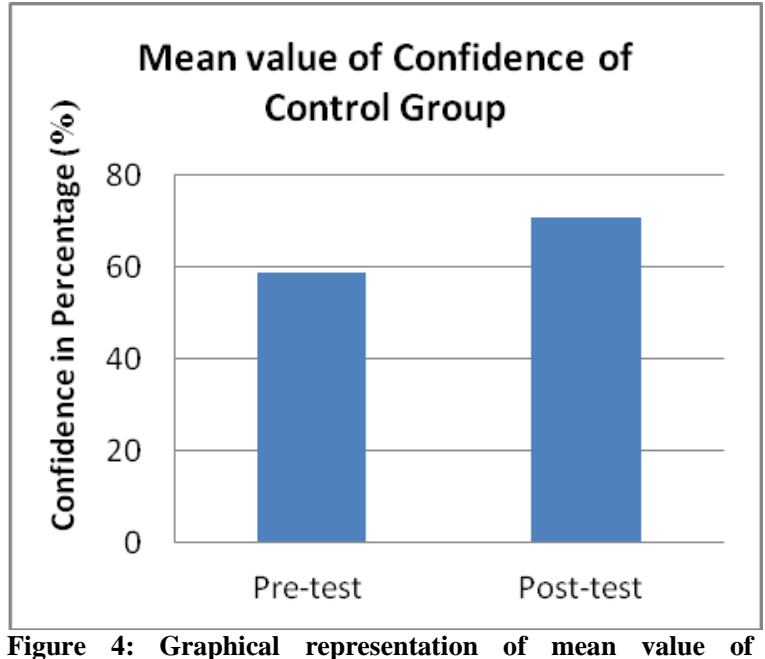

Confidence within control group

Comparison of pre-test and post-test values of Quadriceps strength (Left) within Experimental Group

The Mean column in the pairedsamples $\mathrm{t}$ test table displays the mean pretest and post-test Quadriceps strength (left) scores. The Standard Deviation column displays the standard deviation of the pre and post scores.
The analysis of pre-test and post-test values of Quadriceps strength (left) revealed that there was a difference of 1.97 between the pre test and post test values. t-value calculated was 3.85 which is greater than the table value at $5 \%$ level of significance $(\mathrm{p}<0.05)$.

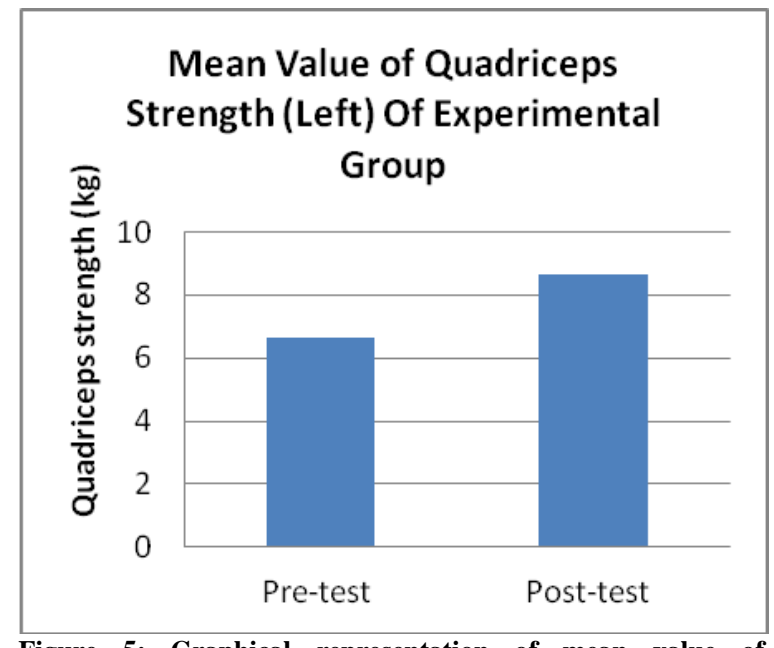

Figure 5: Graphical representation of mean value of Quadriceps Strength (Left) within experimental group

Table 5: Paired t test of Quadriceps (Left) within experimental group

\begin{tabular}{|l|l|l|l|l|l|l|}
\hline Quadriceps Strength (Left) & Mean & Std. Deviation & Mean Difference & t & df & Significance \\
\hline Pre-test & 6.66 & 2.08 & 1.97 & & & \\
\cline { 1 - 5 } Post-test & 8.63 & 2.37 & & 3.85 & 14 & $\mathrm{P}<0.05$ \\
\hline
\end{tabular}


Arun Thachil et.al. Effect of square-stepping exercise in improving lower extremity strength, cadence and confidence among female geriatric population.

Comparison of pre-test and post-test values of Quadriceps strength (Right) within Experimental Group

The Mean column in the pairedsamples $t$ test table displays the mean pretest and post-test Quadriceps strength (right) scores. The Standard Deviation column displays the standard deviation of the pre and post scores.
The analysis of pre-test and post-test values of Quadriceps strength (right) revealed that there was a difference of 2.73 between the pre test and post test values. $\mathrm{t}-$ value calculated was 4.99 which is greater than the table value at $5 \%$ level of significance $(\mathrm{p}<0.05)$.

Table 6: Paired $t$ test of Quadriceps Strength (Right) within experimental group

\begin{tabular}{|l|l|l|l|l|l|l|}
\hline Quadriceps Strength (Right) & Mean & Std. Deviation & Mean Difference & t & df & Significance \\
\hline Pre-test & 6.39 & 2.40 & 2.73 & & & \\
\cline { 1 - 4 } Postest & 9.13 & 3.04 & & 4.99 & 14 & $\mathrm{P}<0.05$ \\
\hline
\end{tabular}

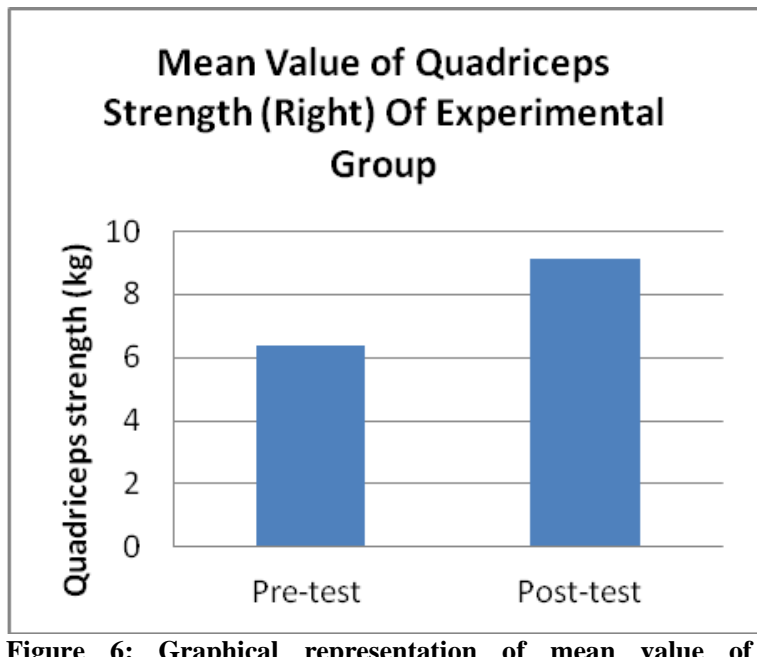

Figure 6: Graphical representation of mean value of Quadriceps Strength (Right) within experimental group

\section{Comparison of pre-test and post-test values of Cadence within Experimental Group}

The Mean column in the pairedsamples $t$ test table displays the mean pretest and post-test cadence scores. The Standard Deviation column displays the standard deviation of the pre and post scores.

The analysis of pre-test and post-test values of cadence revealed that there was a difference of 11.53 between the pre test and post test values. t-value calculated was 3.67 which is greater than the table value at $5 \%$ level of significance $(\mathrm{p}<0.05)$.

Table 7: Paired t test of Cadence within experimental group

\begin{tabular}{|l|l|l|l|l|l|l|}
\hline Cadence & Mean & Std. Deviation & Mean Difference & t & df & Significance \\
\hline Pre-test & 91.13 & 8.66 & 11.53 & & & \\
\cline { 1 - 3 } Post-test & 102.67 & 7.54 & & 3.67 & 14 & $\mathrm{P}<0.05$ \\
\hline
\end{tabular}

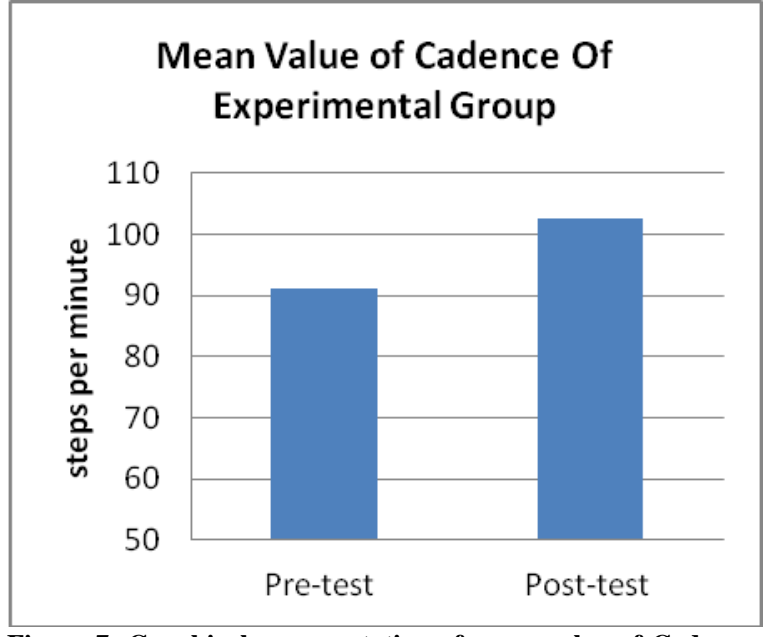

Figure 7: Graphical representation of mean value of Cadence within experimental group
Comparison of pre-test and post-test values of Confidence within Experimental Group

The Mean column in the paired-samples $t$ test table displays the mean pre-test and post-test confidence scores. The Standard Deviation column displays the standard deviation of the pre and post scores.

The analysis of pre-test and post-test values of confidence revealed that there was a difference of 29.62 between the pre test and post test values. t-value calculated was 9.16 which is greater than the table value at $5 \%$ level of significance $(\mathrm{p}<0.05)$.

Table 8: Paired t test of Confidence within experimental group

\begin{tabular}{|l|l|l|l|l|l|l|}
\hline Confidence & Mean & Std. Deviation & Mean Difference & t & df & Significance \\
\hline Pre-test & 55.70 & 14.17 & 29.62 & & & \\
\cline { 1 - 3 } Post-test & 85.33 & 4.41 & & 9.16 & 14 & $\mathrm{P}<0.05$ \\
\hline
\end{tabular}


Arun Thachil et.al. Effect of square-stepping exercise in improving lower extremity strength, cadence and confidence among female geriatric population.

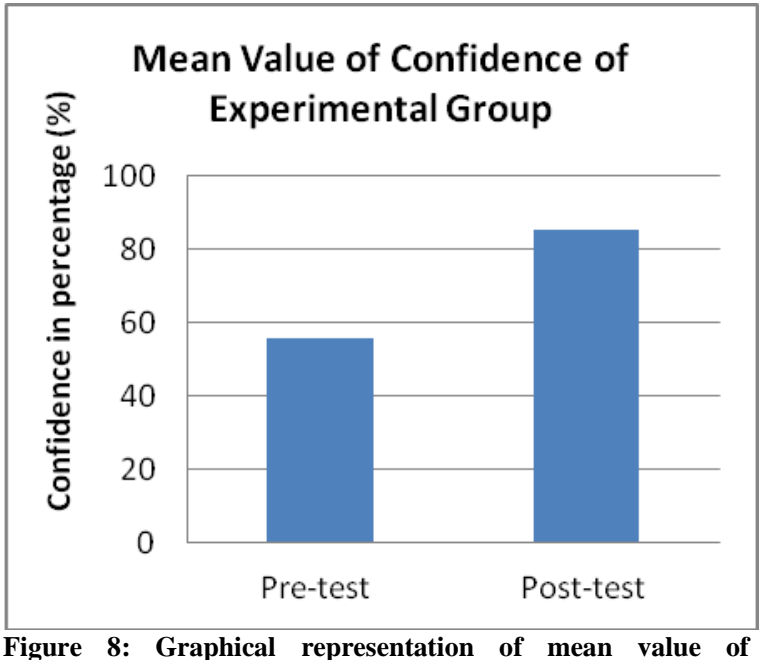

Confidence within experimental group

\section{Comparison of post-test values of Quadriceps strength (Left) between Control and Experimental Group}

The Mean column in the unpairedsamples $t$ test table displays the mean posttest values of Quadriceps strength (left) of the two groups. The Standard Deviation column displays the standard deviation of the post test scores. The analysis of post-test values of Quadriceps strength (left) between the groups revealed that there was a difference of 1.47 between the groups. tvalue calculated was 2.08 which is greater than the table value at $5 \%$ level of significance $(\mathrm{p}<0.05)$.

Table 9: Unpaired t test of Quadriceps strength (Left) between control and experimental group

\begin{tabular}{|l|l|l|l|l|l|l|l|}
\hline Quadriceps Strength (Left) & Mean & Std. Deviation & N & Mean Difference & t & df & Significance \\
\hline Control Group & 7.16 & 1.35 & 15 & 1.47 & & & \\
\cline { 1 - 5 } Experimental Group & 8.63 & 2.37 & 15 & & 2.08 & 28 & $\mathrm{P}<0.05$ \\
\hline
\end{tabular}

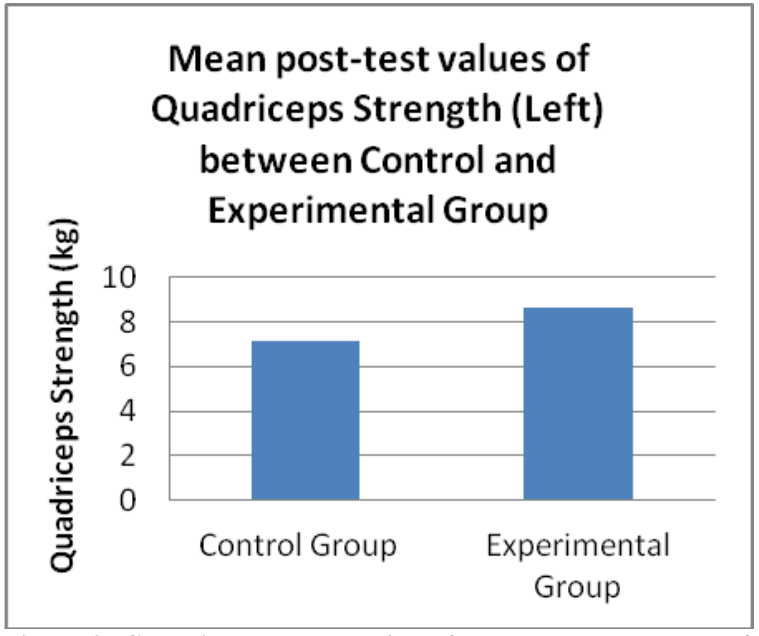

Figure 9: Graphical representation of mean post-test values of Quadriceps strength (Left) between control and experimental group

Comparison of post-test values of Quadriceps strength (Right) between Control and Experimental Group

The Mean column in the unpairedsamples $t$ test table displays the mean posttest values of Quadriceps strength (right) of the two groups. The Standard Deviation column displays the standard deviation of the post test scores. The analysis of post-test values of Quadriceps strength (right) between the groups revealed that there was a difference of 2.14 between the groups. tvalue calculated was 2.26 which is greater than the table value at $5 \%$ level of significance $(\mathrm{p}<0.05)$.

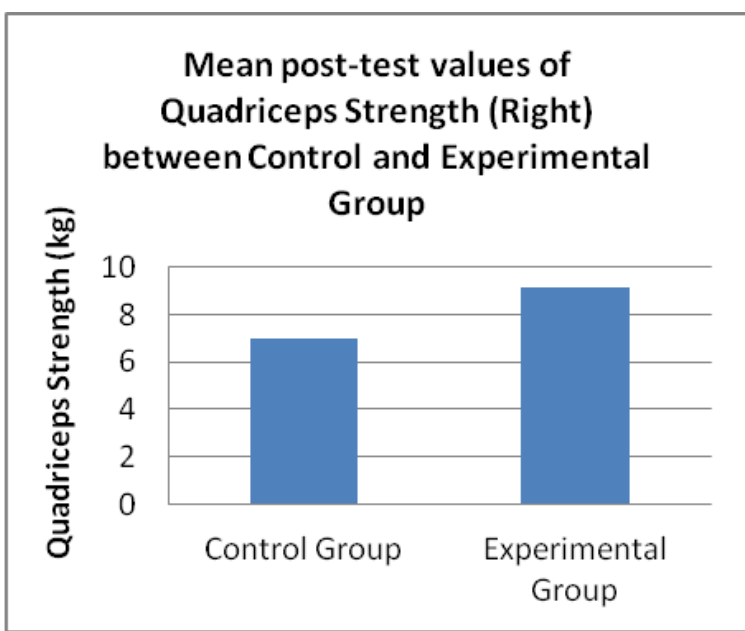

Figure 10: Graphical representation of mean post-test values of Quadriceps strength (Right) between control and experimental group

Table 10: Unpaired t test of Quadriceps strength (Right) between control and experimental group

\begin{tabular}{|l|l|l|l|l|l|l|l|}
\hline Quadriceps Strength (Right) & Mean & Std. Deviation & N & Mean Difference & t & Df & Significance \\
\hline Control Group & 6.98 & 2.05 & 15 & 2.14 & & & \\
\cline { 1 - 5 } Experimental Group & 9.12 & 3.04 & 15 & & 2.26 & 28 & P $<0.05$ \\
\hline
\end{tabular}


Arun Thachil et.al. Effect of square-stepping exercise in improving lower extremity strength, cadence and confidence among female geriatric population.

\section{Comparison of post-test values of Cadence between Control and Experimental Group}

The Mean column in the unpairedsamples $t$ test table displays the mean posttest values of cadence of the two groups. The Standard Deviation column displays the standard deviation of the post test scores. The analysis of post-test values of cadence between the groups revealed that there was a difference of 4.26 between the groups. $t$ value calculated was 1.06 which is less than the table value at $5 \%$ level of significance $(\mathrm{p}>0.05)$.

Table 11: Unpaired t test of Cadence between control and experimental group

\begin{tabular}{|l|l|l|l|l|l|l|l|}
\hline Cadence & Mean & Std. Deviation & N & Mean Difference & T & df & Significance \\
\hline Control Group & 98.4 & 13.58 & 15 & 4.26 & & & \\
\cline { 1 - 5 } Experimental Group & 102.66 & 7.54 & 15 & & 1.06 & 28 & $\mathrm{P}>0.05$ \\
\hline
\end{tabular}

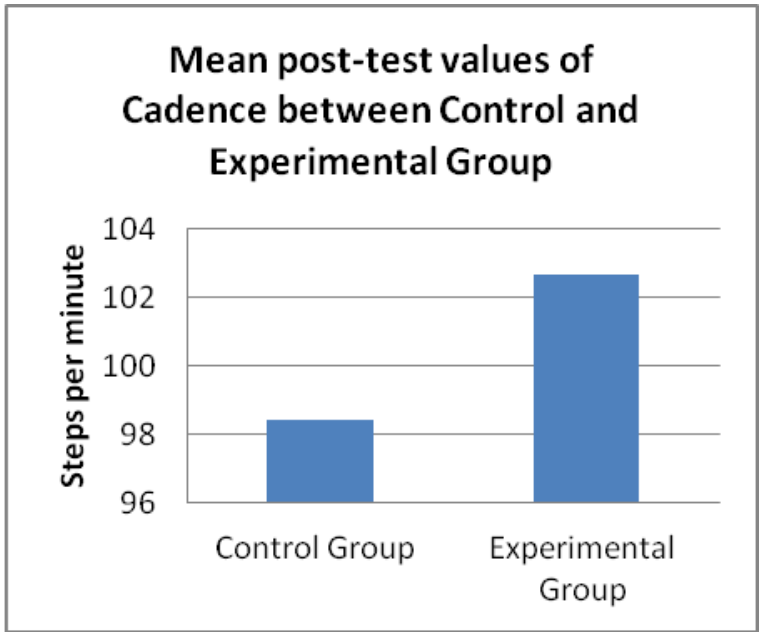

Figure 11: Graphical representation of mean post-test values of Cadence between control and experimental group

\section{Comparison of post-test values of Confidence between Control and Experimental Group}

The Mean column in the unpairedsamples $t$ test table displays the mean posttest values of confidence of the two groups. The Standard Deviation column displays the standard deviation of the post test scores. The analysis of post-test values of confidence between the groups revealed that there was a difference of 14.58 between the groups. t-value calculated was 5.35 which is greater than the table value at $5 \%$ level of significance $(\mathrm{p}<0.05)$.

Table 12: Unpaired $t$ test of Confidence between control and experimental group

\begin{tabular}{|l|l|l|l|l|l|l|l|}
\hline Confidence & Mean & Std. Deviation & N & Mean Difference & t & df & Significance \\
\hline Control Group & 70.74 & 9.58 & 15 & 14.58 & 5.35 & 28 & $\mathrm{P}<0.05$ \\
\cline { 1 - 5 } Experimental Group & 85.32 & 4.41 & 15 & & & & \\
\hline
\end{tabular}

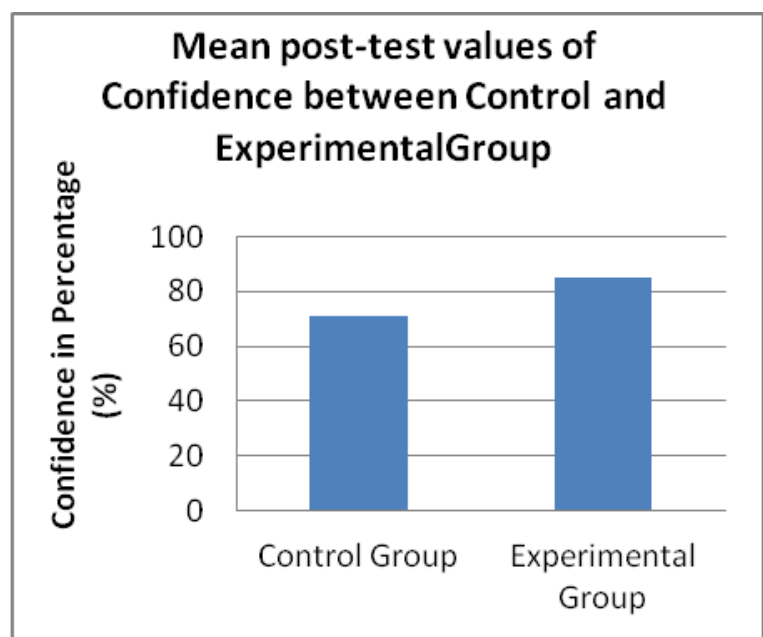

Figure 12: Graphical representation of mean post-test values of Confidence between control and experimental group

\section{DISCUSSION}

Aging is a fundamental process that affects all of our systems and tissues. Falls are frequent among elderly people with advancement in age. Falls represent the most common mechanism of injury, and the leading cause of death from injury, in people older than age 65 years. Fear of fall results in reduced physical activity. Therefore, it is crucial to enhance the mobility of elderly and aimed at improving lower extremity strength, cadence and balance confidence. It is mandatory to design such an exercise program in view of fall prevention. Results demonstrated that, pre-test and post-test analysis using paired $t$ test in both experimental and control group showed that there is improvement in lower extremity strength, cadence and confidence among both the groups but experimental group showed a significant improvement compared to control group. The study was designed to explore the effect of SSE in 
improving lower extremity strength, cadence and confidence.

Within group, comparison of pre and post test data for Quadriceps strength (left) among the experimental group showed significant difference in the paired $t$ test with a mean difference of 1.97 at level of significance less than 0.05 . Quadriceps strength (right) showed a significant difference in the paired t test with a mean difference of 2.73 at level of significance less than 0.05. Cadence showed a significant difference in the paired $t$ test with a mean difference of 11.53 at level of significance less than 0.05 among the experimental group. Confidence showed a significant difference in the paired $t$ test with a mean difference of 29.62 at level of significance less than 0.05 .

While considering the comparison between post-test means of Quadriceps strength (left \& right) among experimental and control group, experimental group shown a high significant difference in the unpaired $t$ test with a mean difference of 1.47 for left Quadriceps strength and 2.14 for right Quadriceps strength at level of significance less than 0.05. With comparison of post-test values of cadence between experimental group and control group, experimental group showed a high significant difference in the unpaired $t$ test with a mean difference of 4.26 at level of significance less than 0.05 , and confidence showed a high significant difference among experimental group with a mean difference of 14.58 .

Significant improvement in quadriceps muscular strength can be justified by the literature support of Ryosuke et $\mathrm{al}^{38}$. According to the study, it is explained that the multidirectional steps in the forward, backward, lateral, and oblique directions during SSE lead to better activation of the synergist and agonist leg muscles. Therefore, it is possible that the SSE regimen consequently improves many aspects of the functional fitness of the lower extremities. This improvement in the strength of the lower extremities enhances the balance of the elderly. We assume that the improvement in balance confidence observed in the present study resulted from the improvement seen in the lower extremity strength which can improve their functional activity.

Ikezoe et $\mathrm{al}^{28}$ noted that the antigravity muscles such as quadriceps, are the most affected by the inactivity. Therefore, the reduced level of functional ability may induce the knee extensor weakness, an important predict factor for falls. Osteoarthritis may be a possible explanation for early decline in knee extensors. Reduced knee extensor strength might lead to poor control of leg movement and slow stepping. When performing alternating stepping in SSE, the leg must exert extension strength to maintain standing balance. This might be the reason for the improvement in quadriceps strength in geriatric population.

Analysis of the post-test mean values of cadence in control group and experimental group was 98.4 and 102.66 with a mean difference of 4.26 . The results shows that there is difference between the mean values within group A and group B, but there is no significant difference in cadence between experimental and control group ( $p>0.05)$. There is no considerable change in the cadence and maintaining the same number of steps. This can be explained and supported by the study done by Hiroyuki Shimada et al, ${ }^{36}$ who examined the relationship between the gait variables with a history of falls and life- space experience among elderly people. The study shown that cadence and step width did not change consistently with aging.

Berihu Fisseha et $\mathrm{al}^{40}$, proposed that SSE was found effective in balance improvement and preventing fear of fall. According to Shigematsu et $\mathrm{al}^{38}$, SSEs were designed based on the principles of proactive and reactive responses enhancement which logically may improve reaction time during corrective stepping during recovering balance after tripping among the older subjects. Further he 
hypothesized that agonist and antagonist muscle contractions in lower extremities during stepping thus improves lower extremity fitness.

The toe walking on the SSE mat with their heels lifted involved small hopping steps and thus improved their leg strength. This is justified by the study done by Pijnappels and colleagues ${ }^{49}$ that during a trip, when the balance of one leg is lost, the other leg is immediately lifted off the floor, in a manner similar to hopping, in order to prevent a fall.

Conventional exercises including forward walking, backward walking, sideways walking and walking on high knees involves unidirectional stepping movements whereas SSE involves varied movements in multiple directions simultaneously. Therefore, it is possible to reveal that the SSE consequently improves functional fitness of lower extremities, which is a modifiable risk factor.

This study reveals that Square stepping exercise can be used as a means of rehabilitation and public health promotion. SSE needs only a low tech equipment with minimum investment. While performing SSE on the square stepping mat, it provides a visual feedback as it denotes the number patterns to be followed and also improves coordination. Enthusiasm, motivation, attention, concentration, competition between the participants, and a dedicative participation was clearly shown by the elderly subjects compared to control group. Supervising several older adults was easy to

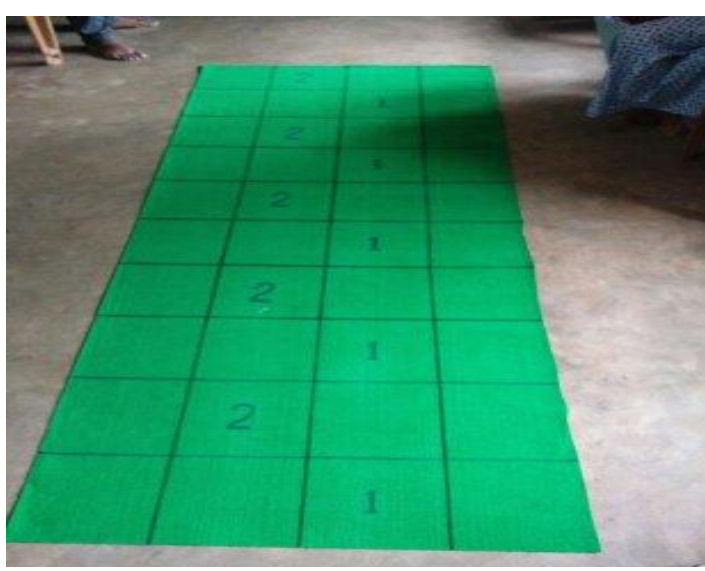

Fig. 3: Elementary 1 carry out as it is performed within a small indoor space.

There is an urgent need to make aware the physiotherapists, other health care professionals, researchers and health care delivery system, to explore and implement SSE as an integral part of fall prevention programme to prevent fall among older adults and to promote aging. Practice training shall be conducted for health care team.

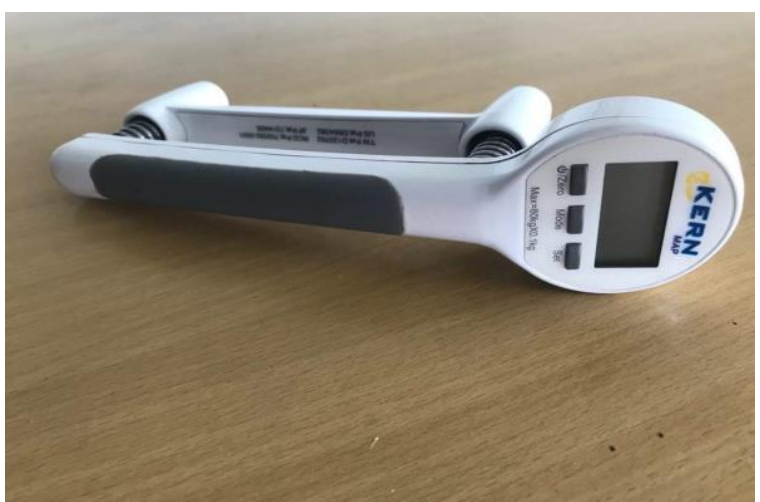

Fig. 1: Handheld Dynamometer

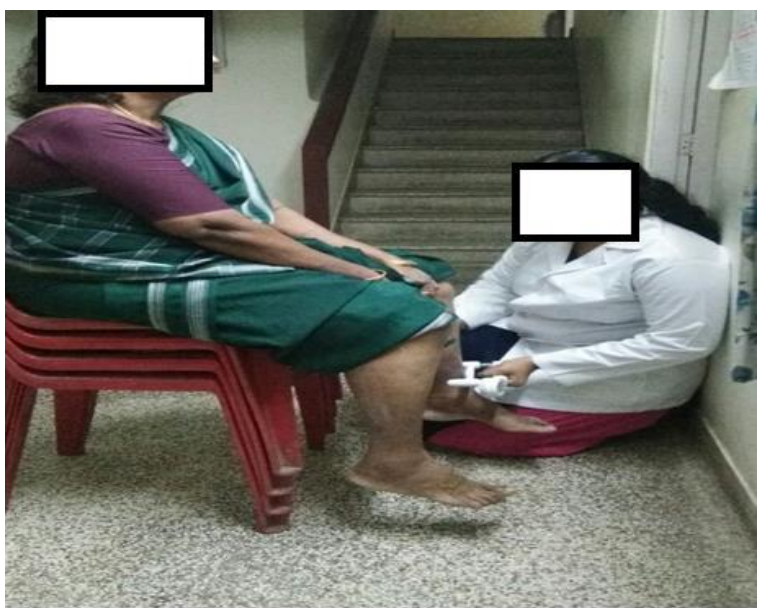

Fig. 2: Quadriceps muscle strength measured by Handheld Dynamometer

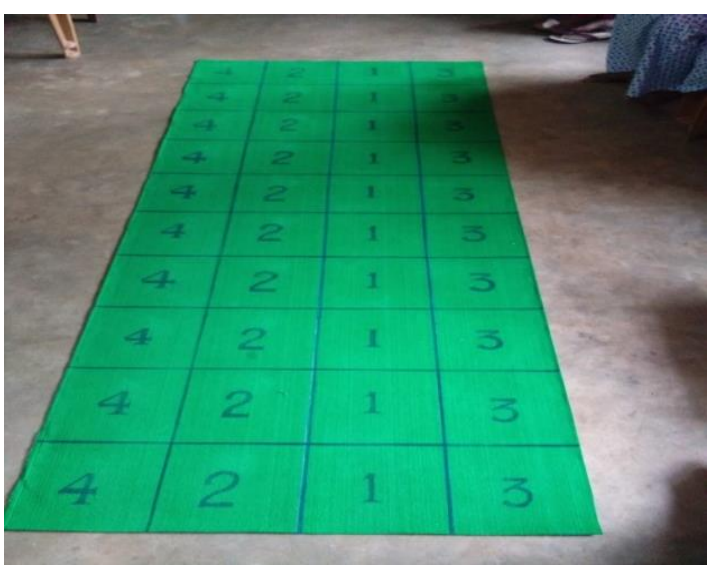

Fig. 4: Elementary 2 
Arun Thachil et.al. Effect of square-stepping exercise in improving lower extremity strength, cadence and confidence among female geriatric population.

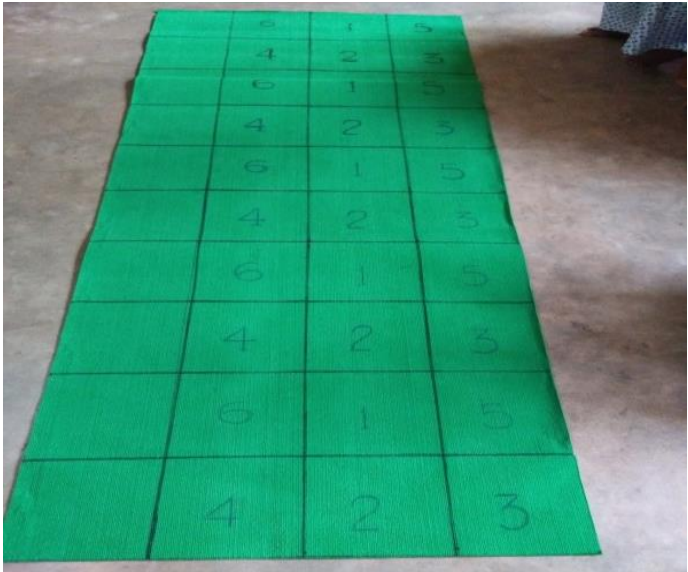

Fig. 5: Intermediate 1

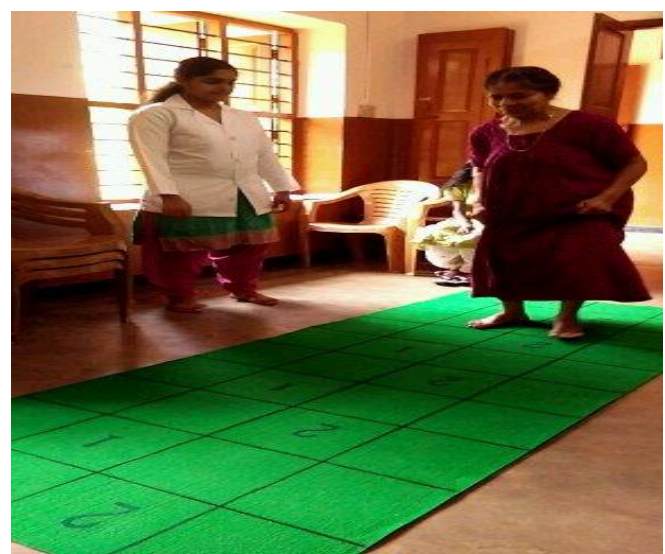

Fig. 7a, b: SQUARE STEPPING MAT

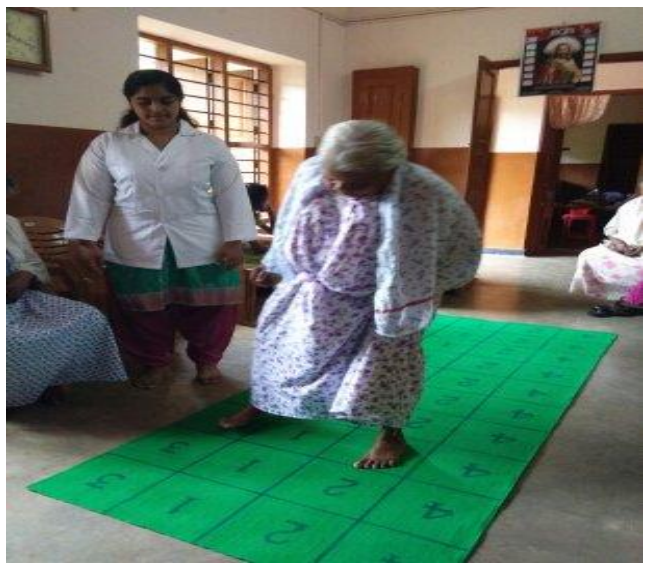

Fig. 8a, b: PARTICIPANTS PERFORMING SQUARE- STEPPING EXERCISE ON MAT
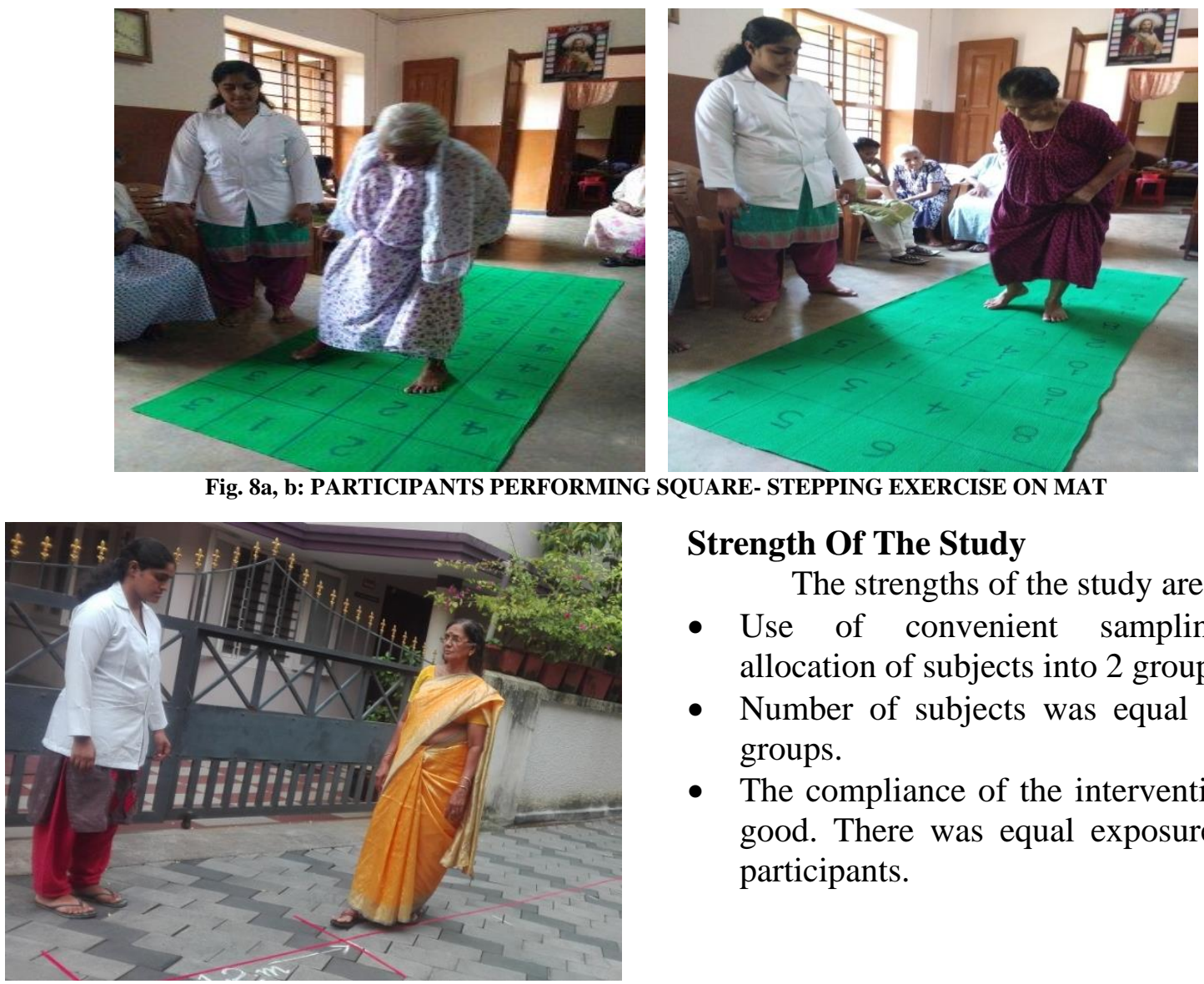

\section{Strength Of The Study}

The strengths of the study are:

- Use of convenient sampling for allocation of subjects into 2 groups.

- Number of subjects was equal in both groups.

- The compliance of the intervention was good. There was equal exposure to all participants.

Fig. 9: 10 METER WALK TEST 
- All the subjects performed training for 4 weeks and all of them completed stepping on 4 mats.

- Use of objective outcome that cannot be influenced by investigators judgement to minimise the risk of bias.

\section{Limitations Of The Study}

1. The study was of short- term duration.

2. The study was done with small sample size.

3. The study included only female subjects within the age group of 65- 75 years.

4. As the measurements were taken manually, this may introduce human error, which could threat the reliability of the study.

5. All measurements were taken by the researcher herself and no blinding of the procedures were done, hence bias can be expected.

6. There was no follow up to see the long term effect of treatment in the present study.

7. Height and weight of the subjects were not included with relation to lower extremity strength and cadence.

8. Since toe walking was given in the SSE program, the plantar flexors goes for strengthening. According to a literature review, it is specified that the muscle strength of knee extensors was associated with many functional activities. The decline of functional activities with aging began earlier in women than in men. ${ }^{27}$ Ikezoe et. al, ${ }^{28}$ noted that the antigravity muscles, such as quadriceps, are the most affected by the inactivity. In addition, knee extensors weakness is the important predict factor for falls. ${ }^{29}$ Because of this reason, quadriceps muscle strength was chosen as outcome in this study and plantar flexor strength was not checked.

\section{Future Implications}

- Future investigations can be conducted in different population and age groups.

- The sample size of subjects should be increased for a more reliable outcome.
- The duration of the study should be increased; hence it may lead to better and valuable results.

- Future studies could examine the effect of Square stepping exercise in improving cardio-respiratory function, and also in the improvement of coordination.

- Since toe walking is incorporated in the SSE program, there is a future scope of study to check the strength of the calf muscle.

- Due to inactivity, the strength of the quadriceps muscle is reduced and disuse atrophy cause reduced muscle bulk. Therefore, muscle girth of the quadriceps muscle should be checked in future study.

- A follow up study could ensure the long term effect of the treatment programme.

\section{CONCLUSION}

The results of the study showed that Square stepping exercise demonstrated a significant improvement in lower extremity strength and confidence as measured by handheld dynamometer and ABC Scale. From the statistical analysis, it is evident that there is no much considerable change in the cadence.

Thus, it can be concluded that Square stepping exercise has a significant effect in improving lower extremity strength and confidence, and reduce risk of fall in young-old female geriatric population. SSE is safe to administer and advantageous to prevent falls.

\section{Source of Funding- Self}

Ethical Clearance- Approved by the institutional Ethical Committee of Medical Trust Hospital on 12.07.2017.Ref. no. $\mathrm{MTH} / \mathrm{EC} / 23$

\section{Acknowledgement: None}

Conflict of Interest: None 
Arun Thachil et.al. Effect of square-stepping exercise in improving lower extremity strength, cadence and confidence among female geriatric population.

\section{REFERENCES}

1. Rogers Me, Rogers NL, Takeshima N, et al.: Methods to assess and improve the physical parameters associated with fall risk in older adults. Prev Med, 2003, 36: 255264.

2. Stuart B. Porter, Physiotherapy Essentials, Tidy's Physiotherapy $15^{\text {th }}$ Edition, 2013 Elsevier Ltd. P550

3. Andrew A. Guccione, Rita A. Wong, Dale Avers, Geriatric Physical Therapy $3^{\text {rd }}$ Edition, 2012, Mosby, Elsevier Inc. Ch 10, 12, 2 p 14, 17, 22, 27, 29, 183, 328, 331, 347,353

4. Narinder Kaur Multani, Satish Kumar Verma; Principles of Geriatric Physiotherapy; First Edition: Jaypee brothers; 2007

5. Dr. B. Krishnaswamy, Dr. Gnanasambandam Usha; Falls in older people national/ regional review India

6. Campbell AJ, Borrie MJ, Spears GF. Risk factors for falls in a community- based prospective study of people 70 years and older. J Gerontol. 1989;44:M112-7.

7. Stevens JA, Corso PS, Finkelstein EA, Miller TR. The costs of fatal and non-fatal falls among older adults. Inj Prev. 2006 Oct;12(5):290-5.

doi: 10.1136/ip.2005.011015. PMID: 17018668; PMCID: PMC2563445.

8. Nordstrom P, Eklund F, Bjornstig U, Nordstrom A, Lorentzon R, Sievanen H, Gustafson Y. Do both areal BMD and injurious falls explain the higher incidence of fractures in women than in men? Calcif Tissue Int.2011;89:203-10.

9. Stevens JA, Ryan G, Kresnow M. Fatalities and injuries from falls among older adults United States, 1993- 2003 and 2001- 2005. JAMA.2007;297:32-3.

10. Mary Jo Storey Gibson. The prevention of falls in later life. A report of the Kellogg International Work Group on the Prevention of falls by the elderly. Dan. Med. Bull.34 1987(suppl.4), 1- 23.

11. Legters K. Fear of falling. Phys Ther 2002; 82: $264-272$

12. Miller CA: The connection between drugs and falls in elders. Geriatric Nurs, 2002, 23: $109-110$

13. Powell LE, Myers AM. The Activitiesspecific Balance Confidence (ABC) Scale, J Gerontol,1995, vol.50 (p.28-34)
14. Myers AM, Fletcher PC, Myers AH, et al. Discriminative and evaluative properties of the Activities- specific Balance Confidence (ABC) Scale, J Gerontol,1998, vol.53 (p.M287-94)

15. Tinetti ME, Richman D, Powell L. Falls efficacy as a measure of fear of falling, $\mathrm{J}$ Gerontol, 1990, vol.45 (p.239-43)

16. Yardley L, Smith H. A prospective study of the relationship between feared consequences of falling and avoidance of activity in community- living older people, Gerontologist,2002, vol. 42 (p.17- 23)

17. Ko YM, Park WB, Lim JY, Kim KW, Paik NJ. Discrepancies between balance confidence and physical performance among community- dwelling Korean elders: a population- based study, Int Psychogeriatr, 2009, vol. 21 (p.738-47)

18. Cumming RG, Salkeld G, Thomas M, et al. Prospective study of the impact of fear of falling on activities of daily living, SF- 36 scores, and nursing home admission, $\mathrm{J}$ Gerontol A Biol Sci Med Sci, 2000, vol.55 (p.299-305)

19. Bradley SM. Falls in older adults. Mt Sinai J Med. 2011 Jul- Aug; 78 (4): 590-5. PMID: 21748747

20. Institution of Medicine (US) Division of Health Promotion and Disease Prevention. Falls in older persons: risk factors and prevention. In: Berg RL, Cassells JS, eds. The Second Fifty Years: Promoting Health and Preventing Disability. Washington, DC: National Academies Press:1992.

21. Centers for Disease Control and Prevention. Injury prevention \& control: traumatic brain injury \& concussion. TBI: get the facts. Updated: September 20, 2016.

22. Carpenter CR, Stern ME. Emergency orthogeriatrics: concepts and therapeutic alternatives. Emerg Med Clin North AM. 2010 Nov; 28 (4): 927- 49. PMID: 20971398.

23. Blain H, Masud T, Dargent- Molina P, et al, for the EU GMS Falls and Fracture Interest Group; European Society for Clinical and Economic Aspects of Osteoporosis and Osteoarthritis (ESCEO); Osteoporosis Research and Information Group (GRIO), and International Osteoporosis Foundation (IOF). A comprehensive fracture prevention strategy in older adults: The European Union Geriatric Medicine Society 
Arun Thachil et.al. Effect of square-stepping exercise in improving lower extremity strength, cadence and confidence among female geriatric population.

(EUGMS) statement. J Nutr Health Aging. 2016; 20 (6): 647- 52.

24. Cenzer IS, Tang V, Boscardin WJ, et al. One- year mortality after hip fracture: development and validation of a prognostic index. J Am Geriatr Soc. 2016 Sep; 64 (9): 1863- 8.

25. Carneiro MB, Alves DP, Mercadante MT. Physical therapy in the postoperative of proximal femur fracture in elderly. Literature review. Acta Ortop Bras. 2013 May; 21 (3): 175- 8.

26. Buecking B, Timmesfeld N, Riem S, et al. Early orthogeriatric treatment of trauma in the elderly: a systematic review and metaanalysis. Dtsch Arztebl Int. 2013 Apr; 110 (15): 255-62.

27. D.Y. Chen. Update therapy in elderly patients with knee osteoarthritis. Int $\mathbf{J}$ Gerontol, 1 (2007), pp. 31-39.

28. T. Ikezoe, N. Mori, M. Nakamura, et al. Atrophy of the lower limb in elderly women: is it related to walking ability ? Eur J Appl, 111 (2011), pp. 989-995.

29. J. D. Moreland, J.A. Richardson, C.H. Goldsmith, et al. Muscle weakness and falls in older adults: a systematic review and meta- analysis J Am Soc, 52 (2004), pp. 1121-1129.

30. Maria Stokes, Emma Stack, et al. Physical Management for Neurological Conditions. Physiotherapy Essentials, $3^{\text {rd }}$ Edition, Churchill Livingstone Elsevier 2012, pp.385, 386.

31. M. E. Tinetti et al. Fear of falling and low self- efficacy: A case of dependence in elderly persons, J Gerontol, 48 (1993), p. 35- 38.

32. Alcalde Tirado P. et al. Fear of Falling, Rev Esp Geriatr Gerontol. 2010 Jan- Feb; 45 (1): 38- 44.

33. Shumway- Cook A, et al. Falls in the Medicare population: incidence, associated factors, and impact on health care. Phys Ther. 2009

34. LM Vitorino et al. Fear of falling in older adults living at home: associated factors. Rev.esc.enferm.USP vol.51, 2017

35. Suey S. Y. Yeung, Esmee M. Reijnierse, Andrea B. Maier, et al. Knee extension strength measurements should be considered as part of the comprehensive geriatric assessment.BMC Geriatr. 2018; 18: 130.

36. Hiroyuki Shimada et al. Relationship between Age- associated changes in Gait and falls and life- space in elderly people. Journal of Physical Therapy Science 22: 419- 424, 2010

37. Chun-Bae Jeon et al.The Effect of Backward Walking Training Methods on Walking in Stroke Patients. J Korean Soc Phys Ther 2011;23(3):21-27

38. Ryosuke Shigematsu, et al. SquareStepping Exercise and Fall Risk Factors in Older Adults: A Single- Blind, Randomized Controlled Trial. Journal of Gerontology: Medical Sciences 2008, Vol. 63A, No. 1, 76-82.

39. Harshika Bhanusali, Vishnu Vardhan, Tushar Palekar, Shilpa Khandare, et al. Comparative study on the effect of Square Stepping exercises versus balance training exercises on fear of fall and balance in elderly population. Int $\mathbf{J}$ Physiother Res 2016, Vol 4 (1) : 1352- 59.

40. Berihu Fisseha, Balamurugan Janakiraman, Asmare Yitayeh, Hariharasudhan Ravichandran, et al. Effect of Square Stepping exercise for older adults to prevent fall and injury related to fall: systematic review and meta- analysis of current evidences. Journal of Exercise Rehabilitation 2017;13(1): 23- 29.

41. S W Parry, et al. Falls and confidence related quality of life outcome measures in an older British cohort. Postgrad Med J. 2001, Vol 77

42. J. Visser, E. Mans, M. de Visser, R.M. Van den Berg, J.H.J Wokke, R.J. de haan. Comparison of maximum voluntary isometric contraction and handheld dynamometry in measuring muscle strength of patients wuth progressive lower motor neuron syndrome. J. Visser et al. Neuromuscular disorder 13, 2003, 744- 750

43. Brent M. Kellen, Patrick O. Mckeon, Laure M. Gountko, and Jay Hertel. Handhelddynamometry: Reliability of lower extremity muscle testing in healthy, physically Active young adults. Journal of sports rehab, 2008,17,160-170.

44. Arnold CM, et al. The reliability and validity of handheld dynamometry for the measurement of lower- extremity muscle strength in older adults. J Strength Cond Res. 2010

45. Benjamin F. Mentiplay, Luke G. Perraton, Kelly J. Bower, Brooke Adair, Yong- Hao Pua, Gavin P. Williams, Rebekah McGaw, Ross A. Clark. Assessment of lower limb 
Arun Thachil et.al. Effect of square-stepping exercise in improving lower extremity strength, cadence and confidence among female geriatric population.

muscle strength and power using hand-held and fixed dynamometry: A reliability and validity study. PLOS One. 2015

46. Bohannon, R.W. Comfortable and maximum walking speed of adults aged 2079 years: reference values and determinants. Age Ageing. 1997

47. Novaes RD, Miranda AS, Dourado VZ. Usual gait speed assessment in middle-aged and elderly Brazilian subjects. Rev Bras Fisioter. 2011 Mar-Apr;15(2):117-22. English, Portuguese. doi: 10.1590/s141335552011000200006. PMID: 21789361.

48. Astha Jain, et al. Impact of static v/s dynamic start on results of 10 metre walk test in patients with acute traumatic brain injury. Indian Journal of Physiotherapy and Occupational Therapy. 2016, Vol.10, No.1,p.11.

49. Pijnappels M, Bobbert MF, van Dieen JH.Push-off reactions inrecovery after tripping discriminate young subjects, older non- fallers and older fallers. Gait Posture. 2005,21:388- 394

How to cite this article: Arun Thachil, Leya Thomas. Effect of square-stepping exercise in improving lower extremity strength, cadence and confidence among female geriatric population. Int $J$ Health Sci Res. 2022; 12(2):287-303. DOI: https://doi.org/10.52403/ ijhsr.20220240 